\title{
Obesity enhances verbal memory in postmenopausal women with Down syndrome
}

\author{
Bindu N. Patel ${ }^{\mathrm{a}}$, Deborah Pang ${ }^{\mathrm{a}}$, Yaakov Stern ${ }^{\mathrm{b}, \mathrm{c}}$, Wayne Silverman ${ }^{\mathrm{a}}$, \\ Jennie K. Kline ${ }^{\mathrm{b}, \mathrm{d}, \mathrm{e}}$, Richard Mayeux ${ }^{\mathrm{b}, \mathrm{c}, \mathrm{f}}$, Nicole Schupf ${ }^{\mathrm{a}, \mathrm{b}, \mathrm{c}, \mathrm{d}, *}$ \\ ${ }^{a}$ Laboratory of Epidemiology, New York State Institute for Basic Research in Developmental Disabilities, \\ 1050 Forest Hill Road, Staten Island, NY 10314, USA \\ ${ }^{\mathrm{b}}$ G.H. Sergievsky Center, Columbia University College of Physicians and Surgeons, Columbia, NY 10032, USA \\ ${ }^{\mathrm{c}}$ The Taub Institute for Research on Alzheimer's Disease and the Aging Brain, Columbia University College of Physicians and Surgeons, \\ 630 West 168th Street, Columbia, NY 10032, USA \\ ${ }^{\mathrm{d}}$ Department of Epidemiology in the Mailman School of Public Health, Columbia University College of Physicians and Surgeons, \\ Columbia, NY 10032, USA

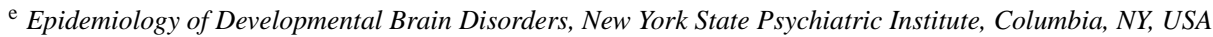 \\ ${ }^{\mathrm{f}}$ Departments of Neurology and Psychiatry, Columbia University College of Physicians and Surgeons, Columbia, NY 10032, USA
}

Received 19 August 2002; received in revised form 11 March 2003; accepted 25 March 2003

\begin{abstract}
Several lines of evidence suggest that the loss of estrogen after menopause may play a role in cognitive declines associated with Alzheimer's disease (AD). In postmenopausal women, the principal source of estrogen is estrone, which is influenced by body mass index (BMI). Increased BMI in postmenopausal women is associated with higher levels of serum estradiol and estrone. We hypothesized that obesity could have a beneficial effect on cognition with advancing age. We compared the performance of healthy nondemented obese and non-obese women with Down syndrome (DS) on a broad spectrum of cognitive tests. Estrone levels were $66.9 \%$ higher in obese than in non-obese postmenopausal women, and $136 \%$ higher in obese than in non-obese premenopausal women. Obese postmenopausal women performed significantly better than non-obese women on measures of verbal memory and on an omnibus test of neuropsychological function, but did not differ significantly in verbal fluency, language, praxis or visuospatial functioning. Among premenopausal women, there was no difference in cognitive function between obese and non-obese women. Our results support the hypothesis that higher endogenous estrogen levels after menopause are associated with better performance on verbal memory.
\end{abstract}

(C) 2003 Elsevier Science Inc. All rights reserved.

Keywords: Down syndrome; Menopause; Estrogen; Obesity; Body mass index; Cognitive function; Alzheimer's disease

\section{Introduction}

Estrogen has neuroprotective actions on the adult brain, and loss of estrogen following menopause may influence cognitive performance and risk for Alzheimer's disease (AD) in aging women [29]. Estrogen increases cholinergic activity $[13,24,44]$, has antioxidant properties [4], and regulates the metabolism of the amyloid precursor protein (APP) to protect against the formation of neurotoxic $\beta$-amyloid $[14,19,34,50]$.

Only a few studies have examined the relationship between endogenous estrogen levels and cognitive function in healthy postmenopausal women. Higher serum levels of to-

${ }^{*}$ Corresponding author. Tel.: +1-212-305-2381; fax: +1-212-305-2426.

E-mail address: ns24@columbia.edu (N. Schupf). tal estrogens were associated with better performance on tests of verbal and visual memory [11,49], but were not associated with improved performance on an overall measure of mental status (MMSE) [35,51].

Estradiol is the principal estrogen in premenopausal women. After menopause, the primary estrogen is estrone, which is formed in adipose tissue, muscle, liver, bone marrow, brain, and fibroblasts from aromatization of circulating androstenedione [16,20]. Increased body mass index (BMI) in postmenopausal women is associated with higher levels of serum estradiol and estrone [10,31]. One study found that increased body weight in women with $\mathrm{AD}$ was correlated with better performance on two measures of global cognitive function [6]. In women with $\mathrm{AD}$, weight loss associated with dementia onset or progression might lead to an association between low body weight and 
cognitive impairment. Determination of the effects of obesity in nondemented postmenopausal women may provide a better test of the beneficial effects of estrone on cognitive function.

In the current study, we examined the effect of obesity on cognition in healthy nondemented women with Down syndrome (DS). DS defined cytogenetically by trisomy 21 , is the most common chromosomal disorder associated with mental retardation, occurring in approximately $1 / 1000$ live births [18]. Women with DS experience early onset of menopause $[9,39,40]$ and develop AD 10-20 years earlier than women in the general population [23]. The high risk for $\mathrm{AD}$ has been attributed to triplication and overexpression of the gene for $\beta$-APP, located on chromosome 21 [38], and virtually all adults with DS have the neuropathological changes associated with $\mathrm{AD}$ by 40 years of age $[25,47]$. Thus, it has been suggested that DS may serve as a model for the study of biological mechanisms involved in the pathogenesis of $\mathrm{AD}$ [22]. Because the interval between onset of menopause and the onset of AD is shorter than is typical in the general population, postmenopausal women with DS provide a unique cohort in which to study the relationship between loss of endogenous estrogen and cognitive decline related to AD. We hypothesized that obese postmenopausal women with DS would have higher levels of estrone and would perform better on tests of cognitive function than non-obese postmenopausal women. In contrast, we expected that there would be no difference in cognitive performance between obese and non-obese premenopausal women because the amount of estrone conversion in premenopausal women is small in comparison with estradiol secretion. Hence, the contribution of increased estrone to overall estrogen activity would be relatively low [54]. To test our hypothesis, we compared the performance of obese and non-obese women with DS on a broad spectrum of cognitive functions.

\section{Methods}

\subsection{Subjects}

Study participants were a community-based sample of 242 women with DS, aged 40-60 years, residing in the New York State. The study participants were ascertained through the statewide service system and recruited with the help of state and voluntary service provider agencies. Subjects were eligible to participate if they had a family member or correspondent who could provide informed consent, and subjects also signed a form acknowledging their willingness to participate. The participation rate among eligible subjects was $74.6 \%$. Recruitment, informed consent, and study procedures were approved by the Institutional Review Boards of the New York State Institute for Basic Research in Developmental Disabilities and Columbia Presbyterian Medical Center and Columbia University Health Sciences.

\subsection{Procedures}

\subsubsection{Ascertainment of menopausal status}

Menopausal status, age of menopause, and use of hormonal replacement therapy/estrogen replacement therapy (HRT/ERT) were ascertained through menstrual chart and medical record review, and survey of primary care physicians and gynecologists. In many residential setting for women with DS, menstrual cycles are charted on a regular basis. For each cycle, the date, duration and severity of flow are noted. We used these menstrual charts, where available, to ascertain menopausal status and age at menopause, and we used final menstrual period (FMP) from the medical chart or physician surveys to ascertain age at menopause when menstrual charts were not available. The correlation between age at menopause ascertained from the different sources was substantial (0.77-0.99), suggesting that ascertainment of menopausal status and age at menopause was reliable. In keeping with convention, we classified age at natural menopause as the age at the last menstrual period preceding cessation of menses for 12 months, in the absence of known causes of amenorrhea (e.g. surgery). We also ascertained whether study participants were being treated with hormone replacement therapy and determined the type, age at onset and duration of the hormone therapy treatment.

\subsubsection{Body mass index}

BMI is a widely used measure of obesity, computed as weight in kilograms divided by height in square meters $\left(\mathrm{kg} / \mathrm{m}^{2}\right)$. BMI was coded into three categories according to NIH clinical guidelines [32]: non-obese $\left(\leq 25.0 \mathrm{~kg} / \mathrm{m}^{2}\right)$, overweight $\left(25.1-29.9 \mathrm{~kg} / \mathrm{m}^{2}\right)$, and obese $\left(\geq 30.0 \mathrm{~kg} / \mathrm{m}^{2}\right)$.

\subsubsection{Assessment of cognitive function}

Participants were evaluated with a neuropsychological battery to assess intellectual functions that are typically affected in $\mathrm{AD}$ and designed for a wide range of intellectual function. The tests included in the battery were based in part on recommendations by the AAMR-IASSMD Working Group for the Establishment of Criteria for the Diagnosis of Dementia in Individuals with Developmental Disability [7].

\subsubsection{Verbal explicit memory}

2.2.4.1. Selective Reminding Test. The Selective Reminding Test [8] is a standard diagnostic tool in the assessment of verbal explicit memory, which provides multiple measures that reflect the efficiency of some of the processing and storage components of memory underlying test performance [21]. We have modified the original structure of the Selective Reminding Test for use with adults with mental retardation, in order to avoid the floor effects that might be encountered if the instrument were utilized as originally constructed [17]. The test consisted of presenting a list of either eight familiar animals or eight familiar foods at a rate of one item per second. Immediately following the list 
presentation, the participants were asked to recall the items presented in any order. The items not recalled on the immediately preceding trial were re-presented and the subject was again asked to recall the entire list. This procedure continued for six consecutive trials. This procedure of selectively reminding participants of those items not recalled allows multiple components of memory functioning to be examined. We used several measures of verbal explicit memory for analysis. Total recall was the total items recalled over the six trials (maximum score $=48$ ). Delayed recall for the list was assessed using a 10-min delay (maximum score $=8$ ). Test-retest reliability was 0.86 for immediate, and 0.55 for 10-min delay. Intrusions are items given at recall, which were not part of the list of items presented. Healthy nondemented adults produce very few intrusions in item recalled, while intrusion tend to increase with cognitive decline [21]. It should be noted that almost without exception, intrusions were from the same semantic category as the test items.

\subsubsection{Global neuropsychological function}

\subsubsection{Down Syndrome Mental Status Examination. The} Down Syndrome Mental Status Examination (DSMSE) is a global measure of neuropsychological function for persons with mental retardation [15]. The DSMSE assesses a broad range of skills that are affected in AD. The test is divided into subtests that test recall for personal information, orientation to season and day of week, memory, language, visuospatial function, and praxis. The total score was used to index overall neuropsychological function. Test-retest reliability for the total score was 0.96 (maximum possible score $=69$ ).

\subsubsection{Test of visuospatial function}

The Block Design subtest from the WISC-R [46] and the Extended Block Design subtest of the DSMSE [15] were used to assess visuospatial function. The WISC-R Block Design subtest was administered according to standard procedures, with the exception that testing always began with item 1 [46]. We used a score based on the sum of scores for both tests as these yield a range of scores that are sufficiently above "floor" effects for almost all subjects. Test-retest reliability $=0.83$ ( maximum possible score $=78$ ).

2.2.6.1. Beery Visual Motor Integration. The Visual Motor Integration test involves copying of simple geometric figures, starting with a vertical or horizontal line and becomes progressively more difficult by adding lines and shapes [3]. It yields a raw score for analysis. Test-retest reliability $=$ 0.91 (maximum possible score $=50$ ).

2.2.6.2. McCarthy verbal fluency. The McCarthy verbal fluency test [28] asks the subjects to name as many animals and foods as they can within $20 \mathrm{~s}$. Test-retest reliability $=$ 0.91 .

\subsubsection{Serum hormone levels}

All laboratory studies were conducted without knowledge of menopausal status or BMI. Blood samples were collected between 10:00 a.m. and 3:00 p.m. Blood was spun in a refrigerated centrifuge and, after separation, sera were frozen at $-20{ }^{\circ} \mathrm{C}$ until assay. Estradiol and estrone were measured by a no-extraction solid-phase ${ }^{125}$ I-radioimmunoassay using commercial kits (Diagnostic Systems Laboratories, Inc., Webster, TX). Sensitivity or minimum detection level for estradiol was $4 \mathrm{pg} / \mathrm{ml}$, and intra-assay and inter-assay coefficients of variation (CV) were 3.8 and $15.2 \%$, respectively. Sensitivity of minimum detection level for estrone was $11 \mathrm{pg} / \mathrm{ml}$ and intra-assay and inter-assay $\mathrm{CVs}$ were 6.3 and $15.8 \%$, respectively. Follicle Stimulating Hormone (FSH), Progesterone (P), Dehydroepiandrosterone sulfate (DHEAS) and Sex-Hormone Binding Globulin (SHBG) were measured by immunometric assays using Immulite systems (Diagnostic Products Corporation, Los Angeles, CA). Sensitivity was $0.1 \mathrm{ml} \mathrm{U} / \mathrm{ml}$ for FSH, $0.2 \mathrm{ng} / \mathrm{ml}$ for $\mathrm{P}, 30 \mu \mathrm{g} / \mathrm{dl}$ for DHEAS, and $0.2 \mathrm{nmol} / 1$ for SHBG. Intraand inter-assay CVs were 6.4 and $7.5 \%$ for $\mathrm{FSH}, 8.0$ and $9.3 \%$ for P, 8.2 and $12 \%$ for DHEAS, and 6.4 and $8.7 \%$ for SHBG, respectively.

\subsubsection{Level of mental retardation}

Level of mental retardation was classified into two groups, based on IQ: (1) mild/moderate (IQ $=35-70$ ); (2) severe/profound (IQ < 20-34).

\subsubsection{Depression}

Depression is associated with weight loss and could have effects on cognitive performance. We ascertained the presence of depression by medical record review and used clinical diagnoses to classify women as depressed or nondepressed. We included depression status in all analyses to control for depression as a potential confounder of the relationship between estrogen and cognitive function.

\subsubsection{Hormone replacement therapy/estrogen replacement therapy (HRT/ERT)}

HRT/ERT is a form of exogenous hormones and can mimic endogenous serum hormones. HRT/ERT was classified as users, nonusers, and unknown (Table 1). Eight women were taking HRT/ERT. Seven of the eight women on HRT/ERT were taking estrogen/progesterone combinations. Six of the eight were taking conjugated estrogens (Prempro), one of the eight was taking estraderm and medroxyprogesterone and the final woman was taking a phytoestrogen. We have adjusted for HRT/ERT in all of our analyses.

\subsection{Statistical analyses}

Healthy nondemented women with DS, who could complete the entire cognitive assessment battery, were included in the analysis. We excluded from the analysis, women: (a) who had never menstruated $(n=6)$, (b) whose menopausal 
Table 1

Demographic characteristics

\begin{tabular}{|c|c|c|c|c|c|c|}
\hline \multirow[t]{2}{*}{ Characteristic } & \multicolumn{3}{|c|}{ Premenopausal women with DS } & \multicolumn{3}{|c|}{ Postmenopausal women with DS } \\
\hline & $\begin{array}{l}\text { Non-obese } \\
(n=5)\end{array}$ & $\begin{array}{l}\text { Overweight } \\
(n=12)\end{array}$ & $\begin{array}{l}\text { Obese } \\
(n=21)\end{array}$ & $\begin{array}{l}\text { Non-obese } \\
(n=22)\end{array}$ & $\begin{array}{l}\text { Overweight } \\
(n=24)\end{array}$ & $\begin{array}{l}\text { Obese } \\
(n=32)\end{array}$ \\
\hline Age (mean \pm S.D.) & $47.9(1.9)$ & $46.8(3.3)$ & $46.7(3.6)$ & $52.4(3.7)$ & $51.0(3.7)$ & $50.4(4.2)$ \\
\hline \multicolumn{7}{|l|}{ Level of function $(n, \%)$} \\
\hline Mild/moderate & $5(100.0)$ & $8(66.7)$ & $10(47.6)$ & $12(54.5)$ & $17(70.8)$ & $24(75.0)$ \\
\hline Severe/profound & - & $4(33.3)$ & $11(52.4)$ & $10(45.5)$ & $7(29.2)$ & $8(25.0)$ \\
\hline Mean body mass index ${ }^{* *}$ & $22.6(2.0)$ & $27.3(0.9)$ & $33.9(3.4)$ & $21.6(2.3)$ & $27.5(1.3)$ & $36.5(6.6)$ \\
\hline \multicolumn{7}{|l|}{ Depression $(n, \%)$} \\
\hline No & $5(100.0)$ & $11(91.7)$ & $21(100.0)$ & $18(81.8)$ & $22(91.7)$ & $26(81.3)$ \\
\hline Yes* & - & $1(8.3)$ & - & $4(18.2)$ & $2(8.3)$ & $6(18.8)$ \\
\hline \multicolumn{7}{|l|}{ HRT/ERT $(n, \%)$} \\
\hline No & $5(100.0)$ & $11(91.7)$ & $21(100.0)$ & $19(86.4)$ & $23(95.8)$ & $27(84.4)$ \\
\hline Yes* & - & $1(8.3)$ & - & $3(13.6)$ & $1(4.2)$ & $5(15.6)$ \\
\hline
\end{tabular}

${ }^{*} P$-value $<0.05 ;$ premenopausal vs. postmenopausal.

** $P$-value $<0.05$; non-obese vs. obese.

status was unknown $(n=9)$, (c) whose HRT/ERT use was unknown (5), (d) who refused to participate after consent $(n=1)$, and (e) women with $\mathrm{AD}(n=33)$. Among postmenopausal women with DS, 78/140 (67.9\% of women with mild/moderate level of function and $32.1 \%$ of women with severe/profound level of mental retardation) could complete all parts of the cognitive assessment battery. Among premenopausal women with DS, 38/60 (60.5\% of women with mild/moderate level of function and $39.5 \%$ of women with severe/profound level of mental retardation) could complete all parts of the battery.

Descriptive statistics were used to examine demographic characteristics and the distribution of obesity, level of mental retardation, depression, and HRT/ERT use. For cross-sectional analysis, we used multivariate analysis of covariance, adjusted for age, level of mental retardation, presence or absence of depression, and HRT/ERT use, to compare performance on the seven measures of cognitive function by obesity level in premenopausal and postmenopausal women. Separate analyses were conducted for premenopausal and postmenopausal women. Post-hoc comparisons used the least significant difference test. We also used multivariate analysis of covariance to compare serum hormone levels by obesity, adjusting for age, level of mental retardation, depression, and HRT/ERT use, in premenopausal and postmenopausal women. Pearson product moment correlations, with adjustment for confounders, were used to assess the relation between hormone levels and cognitive tests. All analyses were conducted using Statistical Package for the Social Sciences (SPSS) 11.0 [43].

Another potential confounder of an association between obesity and cognitive performance is weight loss associated with incipient dementia. Weight loss in patients with AD has been well documented [5,12,36,41]. The National Institute of Neurological and Communicative Disorders and Stroke Task Force on AD has included weight loss as a "clinical feature consistent with the diagnosis of AD [30]." In addi- tion, a prospective study that examined changes in weight over a 20-year interval in community-dwelling adults between the ages of 50 and 79 years found that weight loss precedes onset of dementia, suggesting that weight loss is probably not only a consequence of demented patients being unable to eat independently or refusing to eat [2]. Therefore, we repeated our analyses, excluding women who had more than a $5 \%$ weight loss in the 3 years preceding assessment $(n=21)$, and compared cognitive performance of obese and non-obese postmenopausal women who had had stable weight or weight gain over the past 3 years.

\section{Results}

Postmenopausal women were older than premenopausal women (51.2 years versus 46.9 years; $P<0.000$ ), but did not differ in the distribution of level of mental retardation. The frequency of depression was significantly higher in postmenopausal than in premenopausal women $(14.4 \%$ versus $2.6 \%$ ). However, there were similar numbers of non-obese and obese women who were depressed. All women who used HRT/ERT, except one, were postmenopausal and the distribution of HRT/ERT use was similar between obese and non-obese women. Mean BMI was higher in postmenopausal obese women than in premenopausal obese women (36.5 versus 33.9), but not significantly (Table 1 ).

Among postmenopausal women, obesity was associated with significantly better performance on four out of the seven cognitive tests (obesity main effect, $F_{2,71}=1.6$, $P=0.21$; interaction between obesity and test performance, $F_{2,71}=3.25, P=0.045$ ) (Table 2). On the Selective Reminding Test, significant differences by obesity status were present for total recall $\left(F_{2,77}=3.82, P=\right.$ $0.026), 10 \mathrm{~min}$ recall $\left(F_{2,77}=4.11, P=0.020\right)$, and intrusions $\left(F_{2,77}=3.79, P=0.027\right)$. Post-hoc comparisons showed that obese women performed significantly better 
Table 2

Cognitive test scores (mean \pm S.D.) by obesity

\begin{tabular}{|c|c|c|c|c|c|c|c|c|c|}
\hline \multirow[t]{2}{*}{$\begin{array}{l}\text { Neuropsychological } \\
\text { battery }\end{array}$} & \multicolumn{3}{|c|}{ Premenopausal women: all women } & \multicolumn{3}{|c|}{ Postmenopausal women: all women } & \multicolumn{3}{|c|}{$\begin{array}{l}\text { Postmenopausal women: women } \\
\text { with stable weight }\end{array}$} \\
\hline & $\begin{array}{l}\text { Non-obese } \\
(n=5)\end{array}$ & $\begin{array}{l}\text { Overweight } \\
(n=12)\end{array}$ & $\begin{array}{l}\text { Obese } \\
(n=21)\end{array}$ & $\begin{array}{l}\text { Non-obese } \\
(n=22)\end{array}$ & $\begin{array}{l}\text { Overweight } \\
(n=24)\end{array}$ & $\begin{array}{l}\text { Obese } \\
(n=32)\end{array}$ & $\begin{array}{l}\text { Non-obese } \\
(n=12)\end{array}$ & $\begin{array}{l}\text { Overweight } \\
(n=18)\end{array}$ & $\begin{array}{l}\text { Obese } \\
(n=27)\end{array}$ \\
\hline DSMSE & $65.3(14.0)$ & $57.3(14.1)$ & $64.6(20.9)$ & $55.2(21.8)$ & $57.4(14.9)$ & $63.9(18.1)^{*}$ & $53.6(19.2)$ & $60.4(14.1)$ & $65.1(16.8)^{*}$ \\
\hline \multicolumn{10}{|c|}{ Selective Reminding Test } \\
\hline Total recall & 27.4 & 26.1 & 26. & & 22 . & 28. & & 24. & $5)^{* *}$ \\
\hline $10 \min r$ & 8) & 4. & 4 & 3. & 4. & 5.4 & 3.7 & 4.2 & )$^{* *}$ \\
\hline Total intrusions & $11.6(8.3)$ & 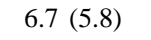 & $5.9(7.4)$ & $13.7(10.5)$ & $9.3(11.1)$ & $6.1(7.6)^{* *}$ & $15.4(11.3)$ & $9.0(11.9)$ & $6.4(7.8)^{* *}$ \\
\hline Verbal fluency test & $9.3(1.7)$ & $8.8(2.3)$ & $7.8(5.5)$ & $5.8(3.4)$ & $6.3(3.5)$ & $7.9(6.2)$ & $4.7(2.1)$ & $7.0(3.4)$ & $7.7(6.4)$ \\
\hline Total block design & $15.6(3.3)$ & $13.1(8.3)$ & $14.8(9.5)$ & $11.4(9.6)$ & $11.8(7.0)$ & $12.9(10.0)$ & $10.4(9.7)$ & $12.6(6.2)$ & $12.2(9.2)$ \\
\hline Beery visual-motor & $10.4(2.5)$ & $9.5(2.9)$ & $10.4(4.6)$ & $9.2(5.1)$ & $9.5(2.0)$ & $9.5(4.3)$ & $9.8(5.4)$ & $10.0(2.1)$ & $9.6(4.2)$ \\
\hline
\end{tabular}

MANCOVA adjusted for age, level of mental retardation, depression, and HRT/ERT use. DSMSE: Down Syndrome Mental Status Examination.

${ }^{*} P<0.1$, obese vs. non-obese postmenopausal women.

** $P<0.05$, obese vs. non-obese postmenopausal women.

than non-obese women on all three measures and significantly better than overweight women on total recall and on $10 \mathrm{~min}$ recall. Among postmenopausal women, the overall association of obesity with performance on the DSMSE was of borderline significance $\left(F_{2,77}=2.64, P=0.079\right)$ (Table 2). Post-hoc comparisons showed that obese women performed significantly better than non-obese women $(P=$ 0.035); however obese women did not perform better than overweight women. There were no statistically significant differences found in any of the other cognitive tests. Among premenopausal women, there were no significant differences in cognitive function between obese and overweight and non-obese women on any of these cognitive measures (Table 2).

A similar pattern of results was observed in analyses restricted to postmenopausal women with stable weight or weight gain over the past 3 years (Table 2). On the Selective Reminding Test, significant differences by obesity status were present for total recall $\left(F_{2,56}=3.39, P=\right.$ $0.042), 10 \mathrm{~min}$ recall $\left(F_{2,56}=3.45, P=0.04\right)$, and intrusions $\left(F_{2,56}=3.33, P=0.044\right)$. Post-hoc comparisons showed that obese women performed significantly better than non-obese women on all three measures, but did not perform significantly better than overweight women on any of the measures. The overall association of obesity with performance on the DSMSE was of borderline significance $\left(F_{2,56}=2.81, P=0.07\right)$ (Table 2). Post-hoc comparisons showed that obese women performed significantly better than non-obese women $(P=0.035)$; however, obese women did not perform better than overweight women.

\subsection{Endogenous hormones and obesity}

Blood samples for hormone assays were available for 58/78 (74.4\%) of postmenopausal women and 30/38 (78.9\%) of premenopausal women. Women with a blood sample did not differ from women without a blood sample in age, level of mental retardation, mean BMI, frequency of depression or ERT/HRT use. As expected, premenopausal women had higher levels of estradiol and lower levels of FSH than postmenopausal women (Table 3). Among postmenopausal women, the mean estrone level was $66.9 \%$ higher in obese than in non-obese women $\left(F_{2,57}=4.82, P=0.012\right)$. Mean FSH levels were $38.2 \%$ and mean SHBG levels were $45.8 \%$ lower in obese women than in non-obese women $\left(F_{2,57}=\right.$ $3.37, P=0.042 ; F_{2,57}=9.30, P=0.000$, respectively).

Table 3

Serum hormone levels (mean \pm S.D.) by obesity

\begin{tabular}{|c|c|c|c|c|c|c|}
\hline \multirow[t]{2}{*}{ Endogenous hormones } & \multicolumn{3}{|c|}{ Premenopausal women with DS } & \multicolumn{3}{|c|}{ Postmenopausal women with DS } \\
\hline & $\begin{array}{l}\text { Non-obese } \\
(n=4)\end{array}$ & $\begin{array}{l}\text { Overweight } \\
(n=11)\end{array}$ & $\begin{array}{l}\text { Obese } \\
(n=15)\end{array}$ & $\begin{array}{l}\text { Non-obese } \\
(n=16)\end{array}$ & $\begin{array}{l}\text { Overweight } \\
(n=17)\end{array}$ & $\begin{array}{l}\text { Obese } \\
(n=25)\end{array}$ \\
\hline Estrone $\left(\mathrm{E}_{1}\right)$ level $(\mathrm{pg} / \mathrm{ml})$ & $25.1(18.2)$ & $40.7(30.9)$ & $59.4(38.9)$ & $25.7(15.9)$ & $19.6(8.5)$ & $42.9(33.7)^{* *}$ \\
\hline Estradiol $\left(\mathrm{E}_{2}\right)$ level $(\mathrm{pg} / \mathrm{ml})$ & $63.2(37.5)$ & $90.1(87.1)$ & $75.8(65.7)$ & $33.6(32.8)$ & $34.3(32.7)$ & $34.6(27.9)$ \\
\hline Progesterone level (ng/ml) & $0(0.2)$ & $1.3(1.7)$ & $1.4(1.7)$ & $0.3(0.2)$ & $0.3(0.2)$ & $0.3(0.2)$ \\
\hline FSH level $(\mathrm{ml} \mathrm{U} / \mathrm{ml})$ & $52.6(17.4)$ & $36.5(28.9)$ & $26.4(21.3)$ & $63.9(37.3)$ & $46.5(25.0)$ & $39.5(26.9)^{* *}$ \\
\hline SHBG level (nmol/l) & $61.7(15.1)$ & $48.7(36.3)$ & $49.0(21.6)$ & $64.9(28.8)$ & $45.4(21.4)$ & $35.2(19.9)^{* *}$ \\
\hline DHEAS level $(\mu \mathrm{g} / \mathrm{dl})$ & $107.2(44.1)$ & $95.7(72.6)$ & $104.4(50.4)$ & $75.6(41.0)$ & $66.5(52.3)$ & $83.2(49.2)$ \\
\hline
\end{tabular}

MANCOVA adjusted for age, level of mental retardation, depression, and HRT/ERT use. DSMSE: Down Syndrome Mental Status Examination.

** $P<0.05$, obese vs. non-obese postmenopausal women. 
Among premenopausal women, estrone was $136.7 \%$ higher in obese than in non-obese women, but the difference in estrone levels failed to reach statistical significance, most likely due to the small number of non-obese premenopausal women $(n=4)$ (Table 3$)$. We used partial correlations to examine the relationship between estrone levels and cognitive performance in postmenopausal women with stable weight, adjusting for age, level of mental retardation, depression, and HRT/ERT use. On measures of verbal explicit memory from the Selective Reminding Test, the adjusted correlation was $r=0.24$ for total recall $(P=0.146), r=0.27$ for $10 \mathrm{~min}$ recall $(P=0.094)$, and $r=-0.23$ for intrusions $(P=$ $0.15)$. On the DSMSE, the adjusted correlation between estrone and test performance was $r=0.37(P=0.022)$.

\section{Discussion}

We found that obese postmenopausal women with DS performed better than both normal weight and overweight women on tests of verbal explicit memory and performed better than normal weight, but not overweight, women on an omnibus test of neuropsychological functioning. The results are consistent with the hypothesis that endogenous estrogen may enhance verbal memory in postmenopausal women with DS. When we repeated the multivariate analysis, including estrone level as a covariate, the association between obesity and cognitive performance was attenuated and failed to reach statistical significance, as would be expected if the enhanced performance of postmenopausal obese women were mediated by estrone (data not shown). Among premenopausal women, conversion of estrone makes a relatively small contribution to total estrogen [54], and our results are consistent in showing only a small, statistically nonsignificant, enhancement of cognitive function in obese premenopausal women compared with non-obese premenopausal women.

Weight loss associated with incipient dementia might produce a spurious association between obesity and cognitive function. In our sample of postmenopausal women with DS, 21 women $(27 \%)$ had more than a $5 \%$ weight loss over the preceding 3 years and 2 of these 21 women (9.5\%) showed cognitive decline within 18 months after these data were collected. When we analyzed the data excluding women who showed weight loss, we obtained the same pattern of results as with the total sample. Obese postmenopausal women performed better on tests of verbal memory and a global neuropsychological exam, although the effects of obesity were not as strong, most likely due to the smaller sample size and lack of statistical power.

Mean estrone levels in postmenopausal obese women with DS were $66.9 \%$ higher than in non-obese women. In contrast, mean sex hormone binding globulin (SHBG) levels were $45.8 \%$ lower in postmenopausal obese women than in non-obese women. In normal weight women, high levels of estrogens have been shown to be associated with elevated
SHBG levels [1]. In obese women, however, SHBG has been found to be significantly lower than in non-obese women [33], and our results show that this effect of obesity is seen in women with DS as well as in women in the general population. The mechanism involved in the lower SHBG levels in obese women compared with normal weight women remains unknown [33,42]. SHBG transports steroid hormones, i.e. estrogens and androgens, in the blood and regulates their bioavalibility to target tissues. The significantly lower SHBG levels in obese women than in normal weight women suggests that bioavailable or free estradiol levels, the components of serum estradiol available to exert biological activity, may be higher in obese than in normal weight women. In one study, healthy nondemented women over 65 years of age with high serum concentrations of non-protein-bound and bioavailable estradiol were less likely to develop cognitive impairment than women with low serum estradiol concentrations [52]. Non-protein bound (free) and loosely bound (bioavailable), rather than total serum estrogen, may be more important in assessing the relationship between estrogen and cognitive function [51,52]. Thus, we speculate that bioavailable and free estradiol levels may contribute, in addition to the effects of estrone, to the enhanced performance on tests of verbal memory that we observed in obese women. Consistent with this observation, serum estrone levels alone were only modestly correlated with cognitive performance. It is also possible that the enhanced performance of obese postmenopausal women on verbal memory may reflect other factors associated with high BMI in addition to serum estrogen levels. A limitation of this study is that we did not have serum hormone levels for all subjects.

In sum, our results suggest that higher endogenous estrogen levels are associated with better performance on verbal memory in postmenopausal women with DS and may have similar effects in women in the general population. However, differences between women with DS and women in the general population in cognitive function, age at menopause and in the distribution of obesity may limit the generalizability of these findings. In addition, virtually all adults with DS show the neuropathological characteristic of AD, including deposition of extracellular $\beta$-amyloid in senile plaques and intracellular accumulation of neurofibrillary tangles by age $35[25,47]$ and most will develop dementia by their seventh decade [22]. Our results also imply that HRT may have beneficial effects on preserving cognitive function in postmenopausal women. These implications need to be examined with care. Recently, the Women's Health Initiative randomized controlled trial of combined estrogen/progestin reported a small but significant increase in coronary heart disease, a nonsignificant increase in invasive breast cancer, and a significant increase in stroke and pulmonary embolism in treated women compared with those on placebo [48]. Thus, the investigators concluded that the overall health risks of the combined estrogen/progestin regimen exceeded its benefits [48]. However, the WHI randomized clinical trial of oral estrogen alone in women with hysterectomy 
continues, since the overall risks and benefits remain uncertain [48]. Factors that could influence the efficacy of postmenopausal hormonal replacement treatment include dosage of estrogen/progestin, other formulations of these hormones, schedules of administration (e.g. tonic or cyclic), or route of administration therapy [26,37,45]. For example, estrogens administrated through a transdermal route might be more effective since this more closely resembles the normal physiology and metabolism of endogenous sex hormones. In several studies, reduced cognitive decline or lower risk of $\mathrm{AD}$ was observed in women who initiated HRT use at menopause or had long-term estrogen use, but was not observed in women with more recent or current exposures $[27,53]$. These findings suggest that there may be a critical period for the beneficial effects of hormone therapy. These alternatives will need to be evaluated in controlled trials.

\section{Acknowledgments}

This work was supported by grant RG3-96-077 from the Alzheimer's Association, by Federal grants AG14673, HD35897, P50AG08702 and by funds provided by New York State through its Office of Mental Retardation and Developmental Disabilities. We thank all the study participants, their families and the state and voluntary agencies for their contribution to the conduct of this study.

\section{References}

[1] Anderson DC. Sex-hormone binding globulin. Clin Endocrinol 1974;3:69-96.

[2] Barrett-Connor E, Edelstein SL, Corey-Bloom J, Wiederholt WC. Weight loss precedes dementia in community-dwelling older adults. J Am Geriatr Soc 1996;44(10):1147-52.

[3] Beery KE, Bukenia NA. Developmental Test of Visual-Motor Integration. Cleveland, OH: Modern Curriculum Press; 1989.

[4] Behl C, Widmann M, Trapp T, Holsboer F. 17-Beta estradiol protects neurons from oxidative stress-induced cell death in vitro. Biochem Biophys Res Commun 1995;216(2):473-82.

[5] Berlinger WG, Potter JF. Low body mass index in demented outpatients. J Am Geriatr Soc 1991;39:973-8.

[6] Buckwalter JG, Schneider LS, Wilshire TW, Dunn ME, Henderson VW. Body weight, estrogen and cognitive functioning in Alzheimer's disease: an analysis of the Tacrine Study Group data. Arch Gerontol Geriatr 1997;24:261-7.

[7] Burt DB, Aylward EH. Test battery for the diagnosis of dementia in individuals with intellectual disability. Working Group for the Establishment of Criteria for the Diagnosis of Dementia in Individuals with Intellectual Disability. J Intellect Disabil Res 2000;44:175-80.

[8] Buschke H. Selective reminding for analysis of memory and learning. J Verbal Learn Verbal Behav 1973;12:543-50.

[9] Carr J, Hollins S. Menopause in women with learning disabilities. J Intellect Disabil Res 1995;39(Pt 2):137-9.

[10] Cauley JA, Gutai JP, Kuller LH, LeDonne D, Powell JG. The epidemiology of serum sex hormones in postmenopausal women. Am J Epidemiol 1989;129(6):1120-31.

[11] Drake EB, Henderson VW, Stanczyk FZ, McCleary CA, Brown WS, Smith CA, et al. Associations between circulating sex steroid hormones and cognition in normal elderly women. Neurology 2000;54(3):599-603.
[12] Franklin CA, Karkeck J. Weight loss and senile dementia in an institutionalized elderly population. J Am Diet Assoc 1989;89:790.

[13] Goodman Y, Bruce AJ, Cheng B, Mattson MP. Estrogens attenuate and corticosterone exacerbates excitotoxicity, oxidative injury, and amyloid beta-peptide toxicity in hippocampal neurons. J Neurochem 1996;66(5):1836-44.

[14] Greenfield JP, Leung LW, Cai D, Kaasi KK, Gross RS, Rodriguez-Boulan E, et al. Estrogen lowers Alzheimer beta-amyloid generation by stimulating trans-Golgi network vesicle biogenesis. J Biol Chem 2002;277(14):12128-36.

[15] Haxby JV. Neuropsychological evaluation of adults with Down's syndrome: patterns of selective impairment in non-demented old adults. J Ment Defic Res 1989;33(Pt 3):193-210.

[16] Hemsell DL, Grodin JM, Brenner PF, Siiteri PK, MacDonald PC. Plasma precursors of estrogen. II. Correlation of the extent of conversion of plasma androstenedione to estrone with age. J Clin Endocrinol Metab 1974;38(3):476-9.

[17] Hill AL, Wisniewski KE, Devenny-Phatate D, Silverman W. Cognitive functioning of older people with Down syndrome. In: Paper Presented at the Eighth International Congress of the International Association for Scientific Study of Mental Deficiency, Dublin, Ireland, August 21-25, 1988.

[18] Hook EB. Rates of Down syndrome in live births and at midtrimester amniocentesis. Lancet 1978;1:1053.

[19] Jaffe AB, Toran-Allerand CD, Greengard P, Gandy SE. Estrogen regulates metabolism of Alzheimer amyloid beta precursor protein. J Biol Chem 1994;269(18):13065-8.

[20] Judd HL, Shamonki IM, Frumar AM, Lagasse LD. Origin of serum estradiol in postmenopausal women. Obstet Gynecol 1982;59(6): 680-6.

[21] Krinsky-McHale SJ, Devenny DA, Silverman WP. Changes in explicit memory associated with early dementia in adults with Down's syndrome. J Intellect Disabil Res 2002;46(3):198-208.

[22] Lai F, Williams RS. A prospective study of Alzheimer disease in Down syndrome. Arch Neurol 1989;46:849-53.

[23] Lai F, Kammann E, Rebeck GW, Anderson A, Chen Y, Nixon RA. APOE genotype and gender effects on Alzheimer disease in 100 adults with Down syndrome. Neurology 1999;53(2):331-6.

[24] Luine VN. Estradiol increases choline acetyltransferase activity in specific basal forebrain nuclei and projection areas of female rats. Exp Neurol 1985;89(2):484-90.

[25] Mann DM, Yates PO, Marcyniuk B. Alzheimer's presenile dementia senile dementia of Alzheimer type and Down's syndrome in middle age form an age related continuum of pathological changes. Neuropathol Appl Neurobiol 1984;10:185-207.

[26] Marder K, Sano M. Estrogen to treat Alzheimer's disease: too little, too late? So what's a women to do? Neurology 2000;54:2035-7.

[27] Matthews K, Cauley J, Yaffe K, Zmuda JM. Estrogen replacement therapy and cognitive decline in older community women. J Am Geriatr Soc 1999;47(5):518-23.

[28] McCarthy D. Scales of children's abilities. San Antonio, TX: Psychological Corporation; 1972.

[29] McEwen BS, Alves SE, Bulloch K, Weiland NG. Ovarian steroids and the brain: implications for cognition and aging. Neurology 1997;48(5 Suppl 7):S8-15.

[30] McKhann G, Drachman DB, Folstein MF, Katzman R, Price D, Stadlan EM. Clinical diagnosis of Alzheimer's disease: report of the NINCDS-ADRDA work group. Neurology 1984;34:939-45.

[31] Meldrum DR, Davidson BJ, Tataryn IV, Judd HL. Changes in circulating steroids with aging in postmenopausal women. Obstet Gynecol 1981;57:624-8.

[32] National Heart Lung and Blood Institute. Clinical guidelines on the identification, evaluation, and treatment of overweight and obesity in adults: executive summary. 1991.

[33] Pasquali R, Casimirri F, Plate L, Capelli M. Characterization of obese women with reduced sex hormone-binding globulin concentrations. Horm Metab Res 1989;22:303-6. 
[34] Petanceska SS, Nagy V, Frail D, Gandy S. Ovariectomy and 17beta-estradiol modulate the levels of Alzheimer's amyloid beta peptides in brain. Neurology 2000;54(12):2212-7.

[35] Polo-Kantola P, Portin R, Polo O, Helenius H, Irjala K, Erkkola R. The effect of short-term estrogen replacement therapy on cognition: a randomized, double-blind, cross-over trial in postmenopausal women. Obstet Gynecol 1998;91(3):459-66.

[36] Renvall MJ, Spindler AA, Ramsdell JW, Paskvan M. Nutritional status of free-living Alzheimer's patients. Am J Med Sci 1989;298:20.

[37] Resnick SM, Henderson VW. Hormone therapy and risk of Alzheimer Disease: a critical time. JAMA 2002;288(17):2170-2.

[38] Rumble B, Retallack R, Hillbach C, Simms G, Multhaup G, Martins $\mathrm{R}$, et al. Amyloid A4 protein and its precursor in Down's syndrome and Alzheimer's disease. N Engl J Med 1989;320:1446-52.

[39] Schupf N, Zigman W, Kapell D, Lee JH, Kline J, Levin B. Early menopause in women with Down's syndrome. J Intellect Disabil Res 1997;41(Pt 3):264-7.

[40] Seltzer GB, Schupf N, Wu HS. A prospective study of menopause in women with Down's syndrome. J Intellect Disabil Res 2001;45(Pt 1):1-7.

[41] Singh S, Mulley GP, Losowksy MR. Why are Alzheimer's patients thin? Age Ageing 1988;17:21-8.

[42] Siiteri PK, Murai JT, Hammond GL, Nisker JA, Raymoure WJ, Kuhn RW. The serum transport of steroid hormones. Recent Prog Horm Res 1982;38:457-503.

[43] Statistical Package for Social Sciences. Chicago, Illinois; 2001.

[44] Toran-Allerand CD, Miranda RC, Bentham WD, Sohrabji F, Brown TJ, Hochberg RB, et al. Estrogen receptors colocalize with low-affinity nerve growth factor receptors in cholinergic neurons of the basal forebrain. Proc Natl Acad Sci USA 1992;89:4668-72.
[45] Toran-Allerand CD. Estrogen as a treatment for Alzheimer's disease. JAMA 2000;284:307-8.

[46] Wechsler D. Wechsler Intelligence Scale for Children-Revised. New York: Psychological Corporation; 1974.

[47] Wisniewski KE, Wisniewski HM, Wen GY. Occurrence of neuropathological changes and dementia of Alzheimer's disease in Down's syndrome. Ann Neurol 1985;17:278-82.

[48] Women's Health Initiative. Risks and benefits of estrogen plus progestin in healthy postmenopausal women: principal results from the Women's Health Initiative randomized controlled trial. JAMA 2002;288:321-33.

[49] Wolf OT, Kirschbaum C. Endogenous estradiol and testosterone levels are associated with cognitive performance in older women and men. Horm Behav 2002;41(3):259-66.

[50] Xu H, Gouras GK, Greenfield JP, Vincent B, Naslund J, Mazzarelli $\mathrm{L}$, et al. Estrogen reduces neuronal generation of Alzheimer beta-amyloid peptides. Nat Med 1998;4(4):447-51.

[51] Yaffe K, Grady D, Pressman A, Cummings S. Serum estrogen levels, cognitive performance, and risk of cognitive decline in older community women. J Am Geriatr Soc 1998;46(7):816-21.

[52] Yaffe K, Lui LY, Grady D, Cauley J, Kramer J, Cummings SR. Cognitive decline in women in relation to non-protein bound oestradiol concentrations. Lancet 2000;356(9231):708-12.

[53] Zandi PP, Carlson MC, Plassman BL, Welsh-Bohmer KA, Mayer LS, Steffens DC, et al. Hormone and replacement therapy and incidence of Alzheimer Disease in older women: the cache county study. JAMA 2002;288(17):2123-9.

[54] Zumoff B, Strain GW, Kream J, O'Connor J, Levin J, Fukushima DK Obese young men have elevated plasma estrogen levels but obese premenopausal women do not. Metabolism 1981;30(10):1011-4. 